\title{
Effect of 0.9\% saline and Ringer's lactate on mean change in blood glucose levels under spinal anaesthesia among diabetic patients
}

\author{
Navdeep Kaur ${ }^{1}$, Balakrishna K Shenoy ${ }^{2 *}$, Suresh Govindswamy ${ }^{1}$, Sadasivan S Iyer ${ }^{1}$ \\ Assistant Professor ${ }^{l}$, Senior Resident ${ }^{2 *}$, Department of Anaesthesiology, Ramaiah Medical College \& \\ Hospitals, Bengaluru, India.
}

\begin{abstract}
Context: It is common practice to avoid lactate-containing intravenous fluids in diabetic patients as it was hypothesized to cause hyperglycaemia by the conversion of lactate to glucose by hepatic gluconeogenesis. However, absence of sound theoretical basis, conflicting reports from numerous clinical trials and improved understanding of biochemistry have necessitated a closer scrutiny of this hypothesis.

Aims: The present study aims to determine the effect of $0.9 \%$ saline and Ringer's lactate on blood glucose levels in the fasting diabetic surgical patients receiving spinal anaesthesia.

Settings and design: The study is a prospective randomized trial conducted on adult patients aged $30-85$ years with well-controlled type 2 diabetes mellitus receiving spinal anaesthesia.

Methods and material: 120 patients with well-controlled type 2 diabetes mellitus receiving spinal anaesthesia were randomized to receive either 1 litre of $0.9 \%$ saline or Ringer's lactate. Blood glucose levels were recorded using a glucometer by the pinprick method before and after infusion of 1 litre of the selected intravenous fluid.

Statistical analysis: Data analysis was done using SPSS statistical package - Version 22.0. Student's unpaired ' $t$ ' test was used to test the significance of difference between quantitative variables. A 'p' value less than 0.05 was taken to denote statistical significance.

Results: Mean change in blood glucose levels after infusion of the intravenous fluid in $0.9 \%$ saline and Ringer's lactate groups were $3.68 \pm 15.2 \mathrm{mg} / \mathrm{dl}$ and $-0.15 \pm 16.5 \mathrm{mg} / \mathrm{dl}$, respectively. The difference between the two groups was not statistically significant with a ' $p$ ' value of 0.188 .

Conclusions: Ringer's lactate solution, when compared to $0.9 \%$ saline, does not cause significant change in the mean blood glucose levels in fasting diabetic patients receiving spinal anaesthesia.
\end{abstract}

Keywords: Ringer's lactate; $0.9 \%$ saline; blood glucose; spinal anaesthesia; diabetes mellitus Key Messages: Ringer's lactate alone does not cause clinically significant hyperglycaemia in fasting diabetic surgical patients. It can be safely used as an alternative intravenous fluid in the perioperative period in patients with well-controlled diabetes mellitus receiving spinal anaesthesia.

\section{Introduction}

India is home to more than 62 million people living with diabetes mellitus ${ }^{1}$ who can potentially present for incidental surgeries and surgeries related to the complications of diabetes mellitus. ${ }^{2}$ Good glycaemic control in the perioperative period is critical in this subset of surgical patients, as numerous studies have established an increase in perioperative morbidity and mortality in diabetic surgical patients than in nondiabetics. ${ }^{3}$
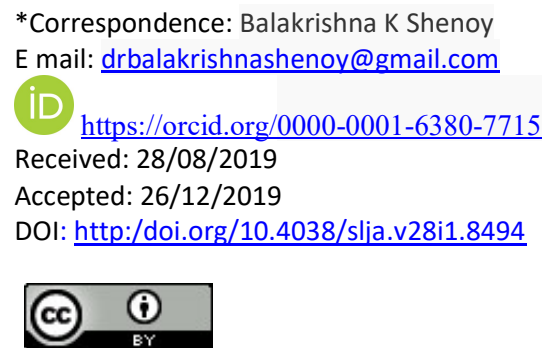

Current recommendations have addressed the optimal blood glucose levels to be maintained in the fasting diabetic surgical patients and the management strategies of continuous insulin infusion regimens as well as oral antihyperglycaemic medications in the perioperative period. ${ }^{3}$ Though intravenous (i.v.) fluids have been used universally to meet the water and electrolyte requirements and to replace the extracellular fluid and blood loss in the perioperative period, ${ }^{4}$ surprisingly few management protocols mention the fluid of choice in diabetic surgical patients. ${ }^{3}$

The widespread practice of avoiding lactatecontaining i.v. fluids in diabetic patients has found a surprising uncritical acceptance despite the absence of sound theoretical basis and paucity of supporting clinical trials. ${ }^{3}$ 
Numerous previous studies comparing $0.9 \%$ saline with Ringer's lactate in surgical patients have shown that regional anaesthesia techniques, like spinal, epidural and nerve blocks, blunt the perioperative neuroendocrine stress responses including the hyperglycaemic response better than general anaesthesia alone. ${ }^{5}$ The findings of these studies suggest that the perioperative glycaemic response may be different in patients receiving general and regional anaesthesia techniques. To the best of our knowledge, there are no studies comparing the effects of Ringer's lactate and $0.9 \%$ saline on the intraoperative glycaemic responses in patients receiving spinal anaesthesia which necessitated the present study.

\section{Subjects and Methods}

In a previous study, it was observed that the mean change in blood glucose levels from preoperative to postoperative for $0.9 \%$ saline and Ringer's lactate groups were $34.4 \pm 70.32 \mathrm{mg} / \mathrm{dl}$ and $64.5 \pm 61.38 \mathrm{mg} / \mathrm{dl}$ respectively. ${ }^{3}$ Expecting to get similar results with precision of $80 \%$ power, $95 \%$ confidence level with minimal detectable difference between the groups of $35 \mathrm{mg} / \mathrm{dl}$ in the result, the present study required a minimum of 56 subjects in each group. It was decided to enroll a total of 120 subjects with 60 subjects in each group.

In this prospective randomized trial, after obtaining institutional approval and informed consent, 120 ASA II patients aged between 30 and 85 years with well-controlled type 2 diabetes mellitus scheduled for elective surgery under spinal anaesthesia were included. Patients with poorly controlled blood glucose levels, impaired renal or liver functions, ischaemic heart disease and those receiving steroid therapy were excluded from the study.

Oral hypoglycaemic agents were omitted in all patients at admission and were switched to regular insulin as per sliding scale. In the operation room, patients were randomized using computer generated randomization into groups ' $\mathrm{N}$ ' and ' $\mathrm{R}$ ' and were allocated to receive 1 litre of either $0.9 \%$ saline or Ringer's lactate respectively. After confirming NPO status, monitoring was commenced with electrocardiogram, pulse oximeter and noninvasive blood pressure and baseline vital signs were noted. Baseline blood glucose level was checked using an Accu-Chek ${ }^{\mathrm{TM}}$ glucometer by the pinprick method and the designated fluid connected.

Spinal anaesthesia was performed with aseptic technique using a 27G Quincke spinal needle at L3-L4 interspace in sitting position and $2.5 \mathrm{ml}$ of $0.5 \%$ bupivacaine was injected. All patients received supplemental oxygen at $6 \mathrm{~L} / \mathrm{min}$ by a simple face mask. Blood glucose level was measured again after infusion of 1 litre of the selected fluid. Mean change in blood glucose levels were noted. Blood glucose levels $<70 \mathrm{mg} / \mathrm{dl}$ and $>200 \mathrm{mg} / \mathrm{dl}$ were respectively considered as hypoglycaemia and hyperglycaemia and were treated accordingly. Any changes in heart rate or blood pressure by more than $30 \%$ of the baseline were recorded and treated accordingly.

\section{Statistical Analysis}

Data analysis was done using SPSS statistical package - Version 22.0. Frequencies and percentages were calculated for qualitative variables. Means and standard deviations were calculated for quantitative variables. Student's unpaired ' $t$ ' test was used to test the significance of difference between quantitative variables (Tables 1 and 2). A 'p' value less than 0.05 was taken to denote statistical significance.

\section{Results}

No significant difference was found between the two groups for age and sex distribution. (Table 1)

Table 1: Profiles of cases studied

\begin{tabular}{|l|l|l|l|l|l|l|l|}
\hline \multirow{2}{*}{ Group } & \multicolumn{3}{|l|}{ Age (years) } & \multicolumn{3}{l|}{ Gender } \\
\cline { 2 - 8 } & & & & \multicolumn{2}{|l|}{ Male } & \multicolumn{2}{l|}{ Female } \\
\cline { 2 - 6 } & Range & Mean & S.D. & No. & \% & No. & $\%$ \\
\hline $\begin{array}{l}0.9 \% \text { saline } \\
\text { group }\end{array}$ & $24-$ & 60.9 & 10.7 & 33 & 55.0 & 27 & 45.0 \\
\hline $\begin{array}{l}\text { Ringer's } \\
\text { lactate group }\end{array}$ & $36-$ & & & & & & \\
\hline 'p' & 84 & & 10.4 & 31 & 51.7 & 29 & 48.3 \\
\hline
\end{tabular}

There was no significant difference in the mean blood glucose levels between the two groups before commencement of fluid infusion indicating comparable glycaemic control between the groups. The mean blood glucose levels after infusion of 1 litre of the test fluid were also comparable between the groups. The change in the mean blood glucose levels after infusion of 1 litre of the test fluid was statistically insignificant. (Table 2) 
Table 2: Change in blood glucose levels in the two groups

\begin{tabular}{|c|c|c|c|c|c|c|}
\hline \multirow[t]{2}{*}{$\begin{array}{l}\text { GRBS } \\
\text { values } \\
(\mathrm{mg} / \mathrm{dl})\end{array}$} & \multicolumn{2}{|c|}{$\begin{array}{l}\text { 0.9\%saline } \\
\text { group }\end{array}$} & \multicolumn{2}{|c|}{$\begin{array}{l}\text { Ringer's } \\
\text { lactate }\end{array}$} & \multirow{2}{*}{$\begin{array}{l}95 \% \\
\text { confidence } \\
\text { intervals } \\
\text { of mean } \\
\text { difference }\end{array}$} & \multirow[t]{2}{*}{ 'p' value } \\
\hline & Mean & S.D. & Mean & S.D. & & \\
\hline $\begin{array}{l}\text { Before } \\
\text { infusion }\end{array}$ & 135.3 & 37.5 & 134.25 & 35.9 & $\begin{array}{l}-1.07 \\
(-12.2- \\
14.34)\end{array}$ & $\begin{array}{l}0.874 \\
\text { Not } \\
\text { significant }\end{array}$ \\
\hline $\begin{array}{l}\text { After } \\
\text { infusion }\end{array}$ & 131.6 & 35.6 & 134.4 & 36.8 & $\begin{array}{l}2.77 \\
(-15.86- \\
10.33)\end{array}$ & $\begin{array}{l}0.676 \\
\text { Not } \\
\text { significant }\end{array}$ \\
\hline Change & 3.68 & 15.2 & -0.15 & 16.5 & $\begin{array}{l}-3.83 \\
(-1.89- \\
9.58)\end{array}$ & $\begin{array}{l}0.188 \\
\text { Not } \\
\text { significant }\end{array}$ \\
\hline
\end{tabular}

No hyper or hypoglycaemic episodes or haemodynamic instability were recorded in either of the groups during the course of the study.

\section{Discussion}

Good glycaemic control in diabetic surgical patients is a cornerstone for reducing morbidity and mortality and improving surgical outcomes in the perioperative period. ${ }^{6}$ Prolonged fasting, discontinuation of routine anti-hyperglycaemic medications, intercurrent infections and inflammation and stress response to surgery and anaesthesia $^{2}$ can cause complications like hypoglycaemia, diabetic ketoacidosis (DKA), hyperglycaemic hyperosmolar syndrome (HHS), delayed wound healing, surgical site infection and sepsis in diabetic surgical patients. ${ }^{6}$

Perioperative management of diabetic surgical patients is not only limited to maintenance of normoglycaemia but also prevention and correction of any accompanying metabolic derangements such as fluid deficits, dyselectrolytaemias and acid-base disorders. Among other management strategies, it is essential to select an appropriate crystalloid i.v. fluid regime which facilitates normal homeostasis in the fasting diabetic patients. Such an ideal crystalloid solution, in addition to being safe, economical and widely available, should be isotonic, contain adequate glucose and potassium to enable insulin infusion to reduce catabolism and should not cause hyperchloraemic acidosis. ${ }^{7}$

Despite the availability of a vast array of i.v. fluids with electrolyte composition similar to that of plasma, $0.9 \%$ saline and Ringer's lactate continue to be the most commonly used i.v. fluids as alternative options are costly and not necessarily safe. ${ }^{3}$
$0.9 \%$ saline, often referred to as "normal saline", contains $9 \mathrm{~g} / \mathrm{L}$ of sodium chloride in water which translates to $154 \mathrm{mmol} / \mathrm{L}$ each of sodium and chloride. From a physiologic viewpoint, the term "normal saline" is a misnomer, as it is anything but normal. ${ }^{8}$ It is hyperosmolar (osmolarity $308 \mathrm{mOsm} / \mathrm{L})$ and acidic $(\mathrm{pH}-5.5)$ to the plasma. It also provides a high sodium load and is grossly hyperchloraemic containing $50 \%$ more chloride than plasma. ${ }^{8}$ Use of $0.9 \%$ saline as the sole IV infusion fluid is associated with complications like hyperchloraemia, acute kidney injury, metabolic acidosis and sodium and water retention leading to organ oedema and dysfunction. $^{8}$

Ringer's lactate is composed of sodium chloride $6 \mathrm{~g} / \mathrm{L}$, sodium lactate $3.1 \mathrm{~g} / \mathrm{L}$, potassium chloride $0.3 \mathrm{~g} / \mathrm{L}$, and calcium chloride $0.2 \mathrm{~g} / \mathrm{L}$. The concentrations of the contained ions are sodium $130 \mathrm{mmol} / \mathrm{L}$, potassium $4 \mathrm{mmol} / \mathrm{L}$, calcium $2.7 \mathrm{mmol} / \mathrm{L}$, chloride $109 \mathrm{mmol} / \mathrm{L}$ and lactate $28 \mathrm{mmol} / \mathrm{L}$. It has an osmolarity of $273 \mathrm{mOsmol} / \mathrm{L}$ and a $\mathrm{pH}$ of 6.5 . Ringer's lactate, thus resembles plasma more closely and as such is a balanced salt solution. ${ }^{8}$

Thomas and Alberti, ${ }^{9}$ in their seminal study, reported transient hyperglycaemia in diabetic patients receiving Hartmann's solution under general anaesthesia. This hyperglycaemia was attributed to the conversion of lactate in Hartmann's solution to glucose by hepatic gluconeogenesis. Based on this observation, they cautioned against the use of any lactate containing IV fluids in diabetic patients. This finding was extrapolated to all lactate containing solutions, including Ringer's lactate, which soon fell out of favour in the management of diabetic patients.

However, a theoretical analysis, as presented, in an editorial by Simpson et al suggested otherwise. ${ }^{7}$ If one litre of Hartmann's solution containing $29 \mathrm{mmol}$ of lactate (3-carbon compound) is infused rapidly and if all the lactate is assumed to be converted to glucose without undergoing oxidative metabolism, a maximum of $14.5 \mathrm{mmol}$ of glucose (6-carbon compound) is obtained. In a $70 \mathrm{~kg}$ patient with an extra cellular fluid (ECF) volume of 12-15 litres, this translates to a maximum increase in glucose concentration by about $1 \mathrm{mmol} / \mathrm{L}$. But in reality, the gluconeogenic pathways are never 
$100 \%$ efficient and some lactate is lost to oxidative metabolism in the peripheral tissues. Thus, for all practical purposes, the increase in ECF glucose concentration is $<1 \mathrm{mmol} / \mathrm{L}$ and any significant hyperglycaemia cannot be attributed to lactate alone. ${ }^{7}$

Review of available literature also revealed conflicting reports. Billiodeaux ST et al, in a retrospective review of medical records, compared blood glucose concentrations in controlled type 2 diabetic patients undergoing carotid endarterectomy under general anaesthesia. They reported no significant change in mean blood glucose levels with Ringer's lactate solution in comparison to normal saline. ${ }^{3}$ Khetarpal $\mathrm{R}$ et al, in their study on nondiabetic patients undergoing elective major noncardiac surgeries under general anaesthesia, reported a significant increase in capillary blood glucose levels with $0.45 \%$ dextrose normal saline in comparison to Ringer's lactate solution. They recommended Ringer's lactate solution as an alternative i.v. fluid for replacement and perioperative maintenance in nondiabetic patients undergoing major surgeries. ${ }^{10}$ Thus, absence of sound theoretical basis and paucity of supporting clinical trials, do not justify the practice of avoiding lactate-containing i.v. fluids in diabetic patients.

In the present study, between the two groups which were matched for age, gender and glycaemic control, the blood glucose levels measured before and after infusion of 1 litre of the selected fluid was comparable both within and across the groups and the difference in the mean blood glucose levels were statistically not significant. These findings indicate that the effect of Ringer's lactate on blood glucose levels is comparable to that of $0.9 \%$ saline and lends credence to the hypothesis that Ringer's lactate alone cannot cause clinically significant hyperglycaemia.

The impact of anaesthesia on the intraoperative and postoperative glycaemic control cannot be understated. The neuroendocrine stress response to surgery can be favourably modulated by the selection of an appropriate anaesthesia technique. $^{5}$ Studies have shown that intraoperative increase in circulating levels of glucagon, cortisol and catecholamines due to surgical stress response under general anaesthesia is effectively blocked by epidural anaesthesia. $^{11}$ Cataract surgeries in type 2 diabetics performed under local anaesthesia caused much less disruption of glucose metabolism when compared with general anaesthesia. $^{12}$ Thus, regional anaesthesia techniques like local infiltration, nerve/ plexus blocks, spinal and epidural anaesthesia can block the surgical stress response and mitigate the perioperative hyperglycaemia., ${ }^{5,10}$ Risk of infection, vascular injury and an exaggerated sympatholytic response in patients with autonomic neuropathies are some of the concerns with regional anaesthesia in diabetic patients. ${ }^{13}$ In the present study, patients receiving only spinal anaesthesia were selected to avoid selection bias and as such the findings may be different in patients receiving other types of anaesthesia and needs further investigation. Further clinical trials are also indicated to study the effects of Ringer's lactate and $0.9 \%$ saline on serum electrolyte levels and acid-base balance in the fasting diabetic patients.

\section{Conclusion}

Ringer's lactate, when compared to $0.9 \%$ saline, does not cause clinically significant hyperglycaemia in fasting diabetic patients receiving spinal anaesthesia. Considering the complications associated with infusion of large volumes of $0.9 \%$ saline alone, the practice of avoiding Ringer's lactate in preference to $0.9 \%$ saline needs to be revisited. Ringer's lactate can be used as a safe alternative intravenous fluid in the perioperative period in patients with wellcontrolled diabetes mellitus receiving spinal anaesthesia.

\section{References}

1. Kaveeshwar SA, Cornwall J. The current state of diabetes mellitus in India. AustralasMed $\mathrm{J}$ 2014;7(1):45-48.

https://doi.org/10.4066/AMJ.2014.1979

2. Schwartz JJ, Akhtar S, Rosenbaum SH. Endocrine Function. In: Barash PG, Cullen BF, Stoelting RK, Cahalan MK, Stock MC, Ortega $\mathrm{R}$, et al, editors. Clinical anaesthesia. 8th ed. Philadelphia: Wolters Kluwer; 2017. pp. 132756.

3. Billiodeaux ST, Samuelson CG, Willett O et al. Intraoperative and postoperative blood glucose concentration in diabetic surgical patients receiving lactated ringer's versus normal saline: a retrospective review of medical records. Ochsner J 2014;14:175-8. 
4. Walsh ES, Traynor C, Paterson JL, Hall GM. Effect of different intraoperative fluid regimens on circulating metabolites and insulin during abdominal surgery. Br J Anaesth1983;55:135-40. https://doi.org/10.1093/bja/55.2.135 PMid:6338893

5. Brull SJ, Akhtar S, Barasch PG, Inzucchi SE. Scientific Principles and Clinical Implications of Perioperative Glucose Regulation and Control. AnaesthAnalg 2010;110:478-97. https://doi.org/10.1213/ANE.0b013e3181c6be63 PMid:20081134

6. Sudhakaran S, Surani SR. Guidelines for perioperative management of the diabetic patient. Surg Res Pract2015;2015:284063. https://doi.org/10.1155/2015/284063

PMid:26078998 PMCid:PMC4452499

7. Simpson AK, Levy N, Hall GM. Peri-operative i.v. fluids in diabetic patients - don't forget the salt. Anaesthesia 2008;63:1043-45. $\underline{\text { https://doi.org/10.1111/j.1365- }}$ $\underline{\text { 2044.2008.05641.x }}$ PMid:18821885

8. Sweeney RM, McKendry RA, Bedi A. Perioperative intravenous fluid therapy for adults. Ulster Med J 2013;82:171-8.

9. Thomas DJ, Alberti KG. Hyperglycaemic effects of Hartmann's solution during surgery in patients with maturity onset diabetes. $\mathrm{Br} J$ Anaesth1978;50:185-8.

https://doi.org/10.1093/bja/50.2.185 PMid:626700

10. Khetarpal R, Chatrath V, Kaur J et al. Impact of different intravenous fluids on blood glucose levels in nondiabetic patients undergoing elective major noncardiac surgeries. Anesth Essays Res 2016;10:425-31. https://doi.org/10.4103/0259-1162.176411 PMid:27746527 PMCid:PMC5062227

11. Moraca RJ, Sheldon DG, Thirlby RC. The role of epidural anaesthesia and analgesia in surgical practice. Ann Surg 2003;238:663-73. https://doi.org/10.1097/01.sla.0000094300.3668 $\underline{\text { 9.ad }}$ PMid:14578727 PMCid:PMC1356143

12. Barker JP, Robinson PN, Vafidis GC et al. Metabolic control of non-insulin-dependent diabetic patients undergoing cataract surgery: comparison of local and general anaesthesia. $\mathrm{Br} \mathrm{J}$ Anaesth1995;74:500-5.

13. https://doi.org/10.1093/bja/74.5.500 PMid:7772420

14. McNulty GR, Robertshaw HJ, Hall GM. Anaesthetic management of patients with diabetes mellitus. $\mathrm{Br} J$ Anaesth2000;85:80-90. https://doi.org/10.1093/bja/85.1.80

PMid:10927997 